Moving Toward and Away From the World: Social Approach and Avoidance Trajectories in Anxious

\title{
Solitary Youth
}

By: Heidi Gazelle and Karen D. Rudolph

Gazelle, H., \& Rudolph, K. D. (2004). Moving toward and away from the world: Social approach and avoidance trajectories in anxious solitary youth. Child Development, 75(3), 829-849.

Made available courtesy of Wiley-Blackwell: The definitive version is available at http://www3.interscience.wiley.com

\section{****Note: Figures may be missing from this format of the document}

\begin{abstract}
:
This investigation tested the person-by-environment hypothesis that the joint influence of behavioral vulnerability (anxious solitude) and interpersonal adversity (peer exclusion) predicts heightened social avoidance and depression over time. The study assessed 519 fifth and sixth graders 3 times during 1 year. Teachers reported social behavior and peer exclusion; youth reported depression. As hypothesized, anxious solitary youth displayed maintenance or exacerbation of social avoidance and depression in the context of high exclusion, but increased social approach and less depression in the context of low exclusion. Some effects were moderated by sex. The interaction of behavioral vulnerability and peer exclusion was more consistently linked to adjustment changes in anxious solitary youth than in youth with other behavioral profiles.
\end{abstract}

\section{Article:}

Theories of personality development have characterized youths' broad social-behavioral orientations as moving toward, away from, or against the world (Caspi, Elder, \& Bem, 1988). Such theories frame youth who display positive social engagement with peers (e.g., sociable behavior) as moving toward the world, youth who display social disengagement from peers (e.g., shy, withdrawn behavior) as moving away from the world, and youth who display conflictual engagement with peers (e.g., aggressive behavior) as moving against the world. Yet, person-by-environment models of adjustment (Magnusson, 1988) emphasize that a person's orientation toward the environment cannot be considered independently of the environment's orientation toward the person. The world also may be conceptualized as moving toward, away from, or against a person. In the realm of peer relations, the peer environment can be viewed as moving toward (positive peer treatment and acceptance), away from (indirect peer exclusion), or against (direct peer exclusion and victimization) a youth.

Growing evidence suggests that youth with similar behavioral orientations can meet with strikingly different responses from the peer environment. For instance, some aggressive youth are marginalized by peers, whereas others are popular and socially dominant (Rodkin, Farmer, Pearl, \& Van Acker, 2000). Differential responses from the peer environment may lead to diverging adjustment pathways among youth who initially display similar vulnerabilities. Specifically, negative environmental responses may reinforce maladaptive social predispositions, leading to continuity in trajectories of adaptational difficulty, whereas positive environmental responses may reshape maladaptive social predispositions, leading to developmental discontinuity and adaptive trajectories. Thus, youth who are prone to behavioral dysregulation (social withdrawal, acting out) may be either reinforced in, or deflected from, trajectories of social and emotional difficulty, depending on the interpersonal environment they encounter.

\section{Anxious Solitude: Moving Away From the World}

The present study examined the developmental trajectories of youth who move away or anxiously withdraw from the peer world. Anxious solitude is characterized by shy, verbally inhibited, and solitary behavior among familiar peers (Coplan, 2000; Rubin, 1982; Rubin \& Clark, 1983). Although this behavioral profile has been characterized as moving away from the world (Caspi et al., 1988), it has been theorized to result from internal 
conflict between normative social approach motivation and abnormally high social avoidance motivation (Asendorpf, 1990). On a motivational level, anxious solitary youth are conceptualized as wanting to interact with peers but paradoxically avoiding peers because of fear that they will be negatively evaluated or mistreated.

The importance of studying anxious solitary youth is underscored by research indicating that they experience persistent difficulties with peer rejection and exclusion, poor social self-concept, loneliness, and depressive symptoms throughout middle childhood and adolescence (e.g., Gazelle \& Ladd, 2003; Hymel, Rubin, Rowden, \& LeMare, 1990; Morison \& Masten, 1991; Rubin, Chen, McDougall, Bowker, \& McKinnon, 1995; Rubin \& Mills, 1988), as well as difficulties with adult developmental tasks, such as entry into marriage and a stable career for men with a childhood history of anxious solitude (Caspi et al., 1988; see also Kerr, Lambert, \& Bem, 1996) and responsive parenting for women with a childhood history of anxious solitude (Serbin et al., 1998). Although research has demonstrated that anxious solitary youth differ from other youth on a host of interpersonal, emotional, and life-transition outcomes, they show a great deal of heterogeneity in adjustment, with some demonstrating significant difficulties and others appearing relatively well adjusted (Asendorpf, 1994; Gazelle \& Ladd, 2003). Yet, little is known about environmental factors in middle childhood and early adolescence that may influence whether anxious solitary youth follow pathways of persistent adjustment difficulty or relative health.

Consistent with a person-by-environment model (Magnusson, 1988), the developmental trajectories of anxious solitary youth may be determined in part by their treatment by peers. Research suggests that anxious solitude co-occurs with peer exclusion, starting as early as kindergarten, and that this co-occurrence continues throughout middle childhood (Gazelle \& Ladd, 2003). Peer exclusion is characterized by being left out of peers' activities through indirect actions (ignoring a youth's attempts to join ongoing conversation, not choosing a youth as a team member) or direct refusals to include a youth ("you can't sit here"). Indirect and direct peer exclusion can be conceptualized as the peer environment moving away from and against a youth, respectively. The present study examined the potential for peer exclusion to modify anxious solitary youths' adjustment trajectories, as reflected in change in social approach and avoidance and emotional adjustment over time.

\section{Social Approach and Avoidance}

Although anxious solitary youths' overall social orientation is characterized by movement away from the peer world, little is known about how specific social approach and avoidance behaviors change over time. Tracking change in these behaviors is essential for understanding how anxious solitary tendencies are translated into interpersonal liabilities and for identifying targets of intervention efforts. The present study examined change in social approach, as manifested in prosocial behavior, and social avoidance, as manifested in socially helpless behavior.

Prosocial behavior is typified by being friendly, helpful, and cooperative with peers. There is evidence that shy youth, on average, engage in less proactive prosocial behavior than other youth (Eisenberg et al., 1996). Evidence suggests that shy individuals experience overwhelming negative emotional arousal during social interactions, which may impede their ability to approach and respond to social partners' needs in an organized prosocial manner (Eisenberg, Fabes, \& Murphy, 1995). However, little is known about peer-related interpersonal circumstances that may lead to change in prosocial engagement over time.

Socially helpless behavior is typified by giving up easily in the face of social challenges and failing to take initiative in social situations. Although helpless behavior and its motivational underpinnings have received substantial attention in the academic domain (for a review, see Skinner, Zimmer-Gembeck, \& Connell, 1998), relatively little is known about helpless behavior in the social domain (for exceptions, see Fincham, Hokoda, \& Sanders, 1989; Nolen-Hoeksema, Girgus, \& Seligman, 1992; Rudolph, Kurlakowsky, \& Conley, 2001). Consistent with theories of motivation that suggest that low perceived self-efficacy and negative attributions of self-competence lead to helpless behaviors (Bandura, 1988/ 1991; Caprara et al., 1999; Dweck \& Leggett, 1988), anxious solitary youth may demonstrate socially helpless behavior because of excessive concerns about 
their own social efficacy or about how peers will treat them. For example, when confronted with a social challenge, such as a disagreement with a peer, anxious solitary youth may defer to the peer's demands rather than risk failure, embarrassment, and mistreatment by attempting to communicate persuasively their perspective. Indeed, research reveals that socially withdrawn youth are unassertive and unlikely to persist with social problem solving following failure during dyadic peer interactions (Stewart \& Rubin, 1995). Yet again, less is known about how circumstances in the peer environment contribute to changes in social helplessness over time in anxious solitary youth.

In keeping with a person-by-environment model (Magnusson, 1988), we anticipated that change in youth's approach versus avoidance behavior with peers over time would be influenced not only by their individual tendency toward anxious solitude but also by the orientation of the peer environment toward them, as reflected in peer exclusion. In regard to initial behavioral characteristics at the outset of the study, it was expected that anxious solitary youth, on average, would display relatively low prosocial behavior and elevated socially helpless behavior among peers. With regard to change, it was hypothesized that nonexcluded anxious solitary youth would display more prosocial and less socially helpless behavior over time, whereas their excluded anxious solitary counterparts would display less prosocial and more socially helpless behavior over time. When anxious solitary youth do not experience exclusion, their social fears may be disconfirmed, supporting a decrease in social avoidance motivation, a consequent increase in the ratio of social approach to social avoidance motivation, and a shift toward behaviors reflecting greater social approach over time. Conversely, when anxious solitary youth encounter exclusion, their social fears are likely confirmed, supporting the maintenance or decrease in the ratio of social approach to avoidance motivation, and maintenance or a shift toward behaviors reflecting social avoidance over time.

\section{Depressive Symptoms}

We also hypothesized that anxious solitude would be more strongly predictive of depressive symptoms in the context of high rather than low peer exclusion. In general, research suggests that anxiety both precedes and contributes to risk for depressive symptoms (e.g., Cole, Peeke, Martin, Truglio, \& Seroczynski, 1998). Consistent with diathesis-stress models of depression (Abramson, Alloy, \& Metalsky, 1988; Alloy, Hartlage, \& Abramson, 1988; Metalsky, Halberstadt, \& Abramson, 1987), we expected that depressive symptoms would most likely emerge when vulnerable, anxious solitary youth experience stressful circumstances. Given the strong link between stress of an interpersonal nature and depression (Rudolph \& Hammen, 1999; Rudolph et al., 2000), we expected peer exclusion to be a particularly salient stressor. According to the helplessnesshopelessness model of anxiety and depression (Alloy, Kelly, Mineka, \& Clements, 1990), anxious individuals perceive themselves to be helpless. That is, they worry that they will experience negative events and doubt their ability to respond effectively to such events. In contrast, depressed individuals are sure they will experience negative events and similarly doubt their ability to cope effectively. Accordingly, anxious solitary youth may worry about being mistreated by peers and feel unable to respond competently, resulting in socially helpless behavior. When they do encounter persistent peer exclusion, they may become convinced that maltreatment by peers is inevitable and that there is nothing they can do to change this situation, leading to depressive hopelessness.

\section{Specificity}

An additional aim of the present study was to investigate whether peer exclusion predicted trajectories of social avoidance and depressive symptoms specifically in anxious solitary youth, or also in youth with other behavioral orientations. In particular, we examined the impact of exclusion on youth who move against the world, as reflected in high levels of aggression, and youth with normative behavioral profiles. Anxious solitary youth may be especially sensitive to peer exclusion because this overt form of peer maltreatment confirms their social fears. However, peer exclusion may be a highly stressful experience for any youth. Thus, the present study examined linkages between peer exclusion and adjustment in youth with anxious solitary and aggressive tendencies as well as those who did not display such behavioral patterns. 


\section{Overview of the Present Research}

Drawing on a person-by-environment model (Magnusson, 1988), this study examined the joint influence of individual vulnerability (anxious solitude) and interpersonal adversity (peer exclusion) on trajectories of social approach, avoidance, and depressive symptoms. Specifically, we hypothesized that anxious solitude would predict continued social avoidance and elevated depressive symptoms over time in the context of high but not low peer exclusion. Conversely, in the absence of peer exclusion, we expected anxious solitary youth to demonstrate improved social approach and depressive symptom trajectories over time, reflecting an underlying motivation to approach the peer world (Asendorpf, 1990). Furthermore, we expected that anxious solitary youth would have a special sensitivity to peer exclusion, such that exclusion would have a greater impact on their adjustment relative to other youth. These processes were examined during early adolescence, a period of social change when youths' trajectories toward or away from the peer world may be especially responsive to peer experiences.

Sex differences in the processes of interest were examined. Previous studies indicate that anxious solitary boys tend to experience greater peer adversity and other adjustment difficulties than do their female counterparts (Caspi et al., 1988; Coplan, Gavinski-Molina, Lagace-Seguin, \& Wichmann, 2001; Gazelle \& Ladd, 2003; Morison \& Masten, 1991; Rubin, Chen, \& Hymel, 1993; Stevenson-Hinde \& Glover, 1996). However, the majority of this evidence originates from studies of young samples. In general, research suggests that interpersonal stress is associated more strongly with emotional difficulties, such as depression, in early adolescent girls than in boys (Rudolph, 2002). Thus, we expected that sex differences in the emotional concomitants of anxious solitude in the early adolescent period might differ from those documented at younger ages.

To test the proposed person-by-environment model, the present study employed a prospective longitudinal design and growth curve analysis using hierarchical linear modeling (HLM; Bryk \& Raudenbush, 1992; Raudenbush \& Bryk, 2002). This statistical technique is well suited for testing anxious solitude and peer exclusion as predictors of initial levels (intercepts) of social approach and avoidance, and depressive symptoms, as well as changes (slopes) in these adjustment outcomes over time. Growth-curve analysis, therefore, provides an ideal approach for testing dynamic change and builds on prior research using traditional techniques less adept at capturing fluid change.

\section{Method}

\section{Participants and Procedures}

Participants were 519 fifth and sixth graders (50\% female; $\mathrm{M}$ age at Wave $1=11.73, \mathrm{SD}=.67)$ with informed consent who were recruited from a mid-sized Midwestern community to participate in the University of Illinois Transition to Adolescence Project (Rudolph \& Clark, 2001; Rudolph et al., 2001; Rudolph, Lambert, Clark, \& Kurlakowsky, 2001).

This study included three waves of data collection, each separated by approximately 6 months, conducted in the spring of one school year and the fall and spring of the following school year. Of those 605 students who participated in a cohort of the larger study, complete teacher measures across all three assessment waves were available for $86 \%$ of the students, yielding the present sample of 519 youth. The majority of nonparticipants at follow-ups were unavailable because of a move to a new district or to absence at all of the assessment sessions.

Participants were representative of the community from which they were sampled in ethnicity (63\% European American, 30\% African American, 4\% Asian American, 0.4\% Latino, 0.2\% Native American; the remaining percentage listed themselves as other or declined to identify themselves) and socioeconomic status, as indexed by school lunch status (33\% federally subsidized lunch). Teachers provided reports of anxious solitude; peer exclusion; and aggressive, prosocial, and socially helpless behavior. Two or three teachers completed these measures across the three waves of the study, thereby reducing the shared-method variance caused by having a 
single informant (although not eliminating any possible bias originating from the shared role of teacher). Youth provided self-reports of depressive symptoms.

\section{Measures}

Table 1 provides intercorrelations among the measures at Wave 1. Intercorrelations were similar in subsequent assessment waves.

Anxious solitude. Anxious solitude was assessed with a measure adapted from the Teacher's Report Form (Achenbach, 1991) and Child Behavior Scale (CBS; Ladd \& Profilet, 1996; see Gazelle \& Ladd, 2003). The eight-item anxious solitude composite includes: "plays alone more than most peers," "self-conscious or easily embarrassed," "'shy or timid," "'refuses to talk," "too fearful or anxious ," " worried," " nervous, highstrung, or tense,' and ' anxious around peers"' $(\alpha \mathrm{s}=.73-.74$, stability $r=.34, p<.001, M \mathrm{~s}=.20-.22, S D \mathrm{~s}=$ .25). All items were rated on a 3 -point scale $(0=$ not true, $1=$ sometimes true, $2=$ often true $)$. Scores were calculated as the mean, with higher scores reflecting higher levels of anxious solitude. Teacher assessment of students' anxious solitary behavior is well validated (e.g., Coplan, 2000; Ladd \& Profilet, 1996; Rubin \& Clark, 1983), and this scale has previously demonstrated moderate convergence with peer behavioral nominations in late childhood.

Table 1

Intercorrelations, Means, and Standard Deviations of Predictor and Criterion Variables at Wave 1

\begin{tabular}{|c|c|c|c|c|c|c|c|c|}
\hline Variable & 1 & 2 & 3 & 4 & 5 & 6 & $M$ & $S D$ \\
\hline 1. Anxious solitude & - & & & & & & 0.21 & 0.25 \\
\hline 2. Peer exclusion & $0.54^{* * *}$ & - & & & & & 0.18 & 0.37 \\
\hline 3. Aggression & $0.15^{* * *}$ & $0.32^{* * *}$ & - & & & & 1.42 & 0.86 \\
\hline 4. Prosocial behavior & $-0.37^{* * *}$ & $-0.44^{* * *}$ & $-0.62^{* * *}$ & - & & & 4.14 & 0.91 \\
\hline 5. Socially helpless behavior & $0.59^{* * *}$ & $0.59^{* * *}$ & $0.53 * * *$ & $-0.61^{* * *}$ & - & & 1.33 & 0.56 \\
\hline 6. Depressive symptoms & $0.27^{* * *}$ & $0.29^{* * *}$ & $0.14^{* *}$ & $-0.16^{* * *}$ & $0.22^{* * *}$ & - & 0.30 & 0.27 \\
\hline
\end{tabular}

${ }^{* *} p<.01 .{ }^{* * *} p<.001$.

Peer exclusion. Peer exclusion was assessed with teacher reports on the CBS (Ladd \& Profilet, 1996). The fiveitem exclusion composite includes: "peers avoid this student," "excluded from peers' activities," "peers refuse to let this student play with them," "not chosen as a playmate by peers," and "wants to play with others but they don't want to play with him or her' $(\alpha \mathrm{s}=.90-.93$, stability $r=.35, p<.001, M \mathrm{~s}=.17-.18, S D \mathrm{~s}=.37-$ .39). Ratings were made on the same 3-point scale described earlier, and items were averaged. The convergent validity of this scale is supported by correlation with the self-report item "I am left out of games or other kids' activities at school"' $(r=.30, p<.001)$ in the present study and with peer-reported exclusion in late childhood in a previous study (Gazelle \& Ladd, 2003). Confirmatory factor analysis (CFA) indicated an adequate twofactor fit for anxious solitude and peer exclusion in the present investigation: $\chi^{2} / d f=3.09$, comparative fit index $(\mathrm{CFI})=.96$, root mean square error of approximation $(\mathrm{RMSEA})=0.065, p<.05$. Additional evidence of discriminant validity is provided by previous two-factor CFAs of anxious solitude and peer exclusion (Bowker, Bukowski, Zargarpour, \& Hoza, 1998; Gazelle \& Ladd, 2003).

Aggressive behavior. Aggressive behavior was assessed with the Teacher Assessment of Social Behavior (TASB; Cassidy \& Asher, 1992). The three-item subscale includes: "starts fights," "mean to peers," and "hurts peers" ( $\alpha \mathrm{s}=.87-.91$, stability $r \mathrm{~s}=.38-.61, p \mathrm{~s}<.001, \mathrm{Ms}=1.38-1.43, \mathrm{SDs}=.79-.86)$. All items were rated on a 5 -point scale $(1=$ very uncharacteristic, $3=$ neutral, $5=$ very characteristic $)$. Scores were calculated as the mean, with higher scores representing more aggression. Past research has validated the TASB with early adolescents (Rudolph \& Clark, 2001). 
Prosocial behavior. Prosocial behavior also was assessed with the TASB (Cassidy \& Asher, 1992). The threeitem subscale includes: "friendly and nice to other youth," " helpful toward other youth," "cooperative with other youth-he/she shares and takes turns"' $(\alpha \mathrm{s}=.83-.87$, stability $r \mathrm{~s}=.39-.65, p \mathrm{~s}<.001, M \mathrm{~s}=3.93-4.14$, $S D$ s $=.91-1.00)$. Ratings were made on the 5-point scale described earlier, and items were averaged, with higher scores indicating more prosocial behavior.

Socially helpless behavior. Teachers completed the 12-item Social Helplessness Scale (Fincham et al., 1989; Nolen-Hoeksema et al., 1992), an assessment of helpless behavior in the context of peer interactions. Sample items include: "takes little independent initiative in making friends," "shows little persistence when trying to get along with a classmate," and "is easily discouraged in his/her attempts to get along with a classmate"' $(\alpha \mathrm{s}=$ $.92-.94$, stability $r \mathrm{~s}=.39-.69, \mathrm{~s}<.001, \mathrm{Ms}=1.28-1.35, S D \mathrm{~s}=.54-.63)$. All items were rated on a 5-point scale $(1=$ not true, $3=$ somewhat true, $5=$ very true $)$. Scores were calculated as the mean, with higher scores reflecting more socially helpless behavior. This measure has been well validated in past research with early adolescents (Nolen-Hoeksema et al., 1992; Rudolph et al., 2001).

Depressive symptoms. Depressive symptoms were assessed with the Children's Depression Inventory (CDI; Kovacs, 1980-1981). This measure includes 27 items that reflect a variety of symptoms associated with depression (e.g., "I am sad all the time"' and "I am sure that terrible things will happen to me'"). Three items were discarded to avoid confounds with aggressive behavior (e.g., "I get into fights all the time") and one suicide item was dropped before assessment because of concerns of the schools, yielding a final scale of 23 items $(\alpha \mathrm{s}=.86-.89$, stability $r \mathrm{~s}=.47-.63, p \mathrm{~s}<.001, M \mathrm{~s}=.26-.30, S D \mathrm{~s}=.27-.29)$. Each item presents three response alternatives ranging in severity from 0 to 2 . Youth indicated which alternative best described how they had been feeling in the past 2 weeks. Scores across the 23 items were averaged, with higher scores reflecting greater severity and frequency of symptoms. The CDI has well-established reliability and validity (Kovacs, 1980-1981; Smucker, Craighead, Craighead, \& Green, 1986). Of the 519 participants, self-reported depressive symptoms were available for $98 \%$ at Wave $1,96 \%$ at Wave 2, and $87 \%$ at Wave 3 . A strength of HLM is that it is well suited for handling missing data (Bryk \& Raudenbush, 1992). Consequently, only 1 of the 519 participants was dropped from analyses involving depressive symptoms because of missing self-report data at each wave.

Sex and grade. Sex was effect coded (girl $=-1$, boy $=+1$ ). In subsequent sections, negative sex coefficients indicate higher levels of the criterion for girls, and positive sex coefficients indicate higher levels of the criterion for boys. Similarly, grade was effect coded (fifth grade $=-1$, sixth grade $=+1$ ), such that negative grade coefficients indicate higher levels of the criterion for fifth graders, and positive grade coefficients indicate higher levels of the criterion for sixth graders.

\section{Results}

Overview of Analyses

Growth-curve analysis using HLM (Bryk \& Raudenbush, 1992; Raudenbush \& Bryk, 2002) was the primary method of analysis. Growth-curve analysis is a two-step procedure. First, the trajectory of the dependent variable over time is estimated for every individual. The purpose of this Level 1 analysis is to test whether there is enough individual variation in trajectories relative to the mean (overall trajectory of all youth in the sample) to warrant specifying between-subjects independent variables at Level 2 in the second step of analysis. The initial analysis is referred to as unconditional because it contains no Level 2 variables. If significant individual variation is found in trajectories of the dependent variable over time in the unconditional analysis, the second step of analysis examines between-subjects effects by specifying independent variables (e.g., anxious solitude, exclusion) at Level 2. The dependent variables at Level 2 are the individual intercepts and slopes derived from Level 1 analysis. This second step of analysis is referred to as conditional. These analyses tested the hypotheses that (a) high anxious solitude predicts low initial levels of social approach and high initial levels of social avoidance and depressive symptoms, and (b) the interaction of anxious solitude and peer exclusion predicts change in social engagement and depressive symptoms over time, such that high anxious solitude in the context 
of high exclusion predicts maintenance or exacerbation of social avoidance and depressive symptoms over time, whereas high anxious solitude in the context of low exclusion predicts improving social approach and depressive symptoms over time.

Both continuous and group versions of each growth curve model were performed. We expected that the continuous and group versions of the models would be consistent with each other overall and would complement each other in several ways: (a) similar findings from continuous and group approaches reinforce confidence in findings, especially confidence in analyses involving groups of modest size; (b) group analysis permits a person-oriented approach by examining how a combination of characteristics operate within individual systems that are homogenous in nature (Magnusson, 1988); and (c) continuous analysis permits the examination of interactions among variables and the unique predictive power of each variable after accounting for other variables.

Results of continuous analyses are graphically represented by substituting values at $\pm 1 S D$ of the independent variable into the hierarchical models derived from analyses. For instance, the trajectory of a prototypical youth high in both anxious solitude and exclusion would be graphed as follows, assuming significant effects for anxious solitude and exclusion at both the intercept and linear slope, as well as a significant Anxious Solitude $\times$ Exclusion interaction in slope:

$$
\begin{aligned}
\pi_{0 i}+\pi_{1 i}= & \beta_{00}+\beta_{01}(\text { anx. })+\beta_{02}(\text { ex. })+\beta_{10}(\text { time }) \\
& +\beta_{11}(\text { anx. })(\text { time })+\beta_{12}(\text { ex. })(\text { time }) \\
& +\beta_{13}(\text { ex. })(\text { time }) .
\end{aligned}
$$

In this equation, $\pi_{0 i}$ is the intercept (Wave 1 criterion value) for individual $i$, and $\pi_{1 i}$ is the linear slope (change in the criterion over time) for individual $i$. $\beta_{00}$ is the coefficient for the mean intercept, $\beta_{10}$ is the coefficient for the mean slope, $\beta_{13}$ is the slope coefficient for the interaction between anxious solitude and exclusion, and all other $\beta$ s are coefficients for the variables by which they are multiplied. Anx. =1SD for anxious solitude; ex. = $1 S D$ for exclusion; and time $=0$ at Wave 1, 1 at Wave 2, and 2 at Wave 3. Because the proposed person-byenvironment model emphasizes how the association between individual vulnerability (anxious solitude) and adjustment trajectories (social disengagement, depression) is moderated by circumstances in the interpersonal environment (peer exclusion), all Anxious Solitude $\times$ Exclusion interactions were graphed at \pm 1 SD for exclusion. Only significant effects were graphed.

HLM output yields parameters for trajectories significantly different from the prototypical trajectory of all youth not identified in extreme groups (or in continuous analyses, the prototypical trajectory of youth who score at the mean on all predictor variables). Because the prototypical trajectory is mathematically obtained for scores of zero on all variables present in the model, variables are scaled such that zero represents the mean for continuous variables (i.e., centered variables), the point midway between dichotomous groups (effect coded $(+1$, -1) sex), or nondeviant group membership (for dummy coded behavioral groups). In analyses containing both sexes, the prototypical trajectory is sex neutral. We refer to prototypical trajectories as mean trajectories.

Significant differences among group intercepts were tested using the formula:

$$
t=\beta_{1}-\beta_{2} / \sqrt{S E_{1}^{2}+S E_{2}^{2}} \text {. }
$$

The same $t$ test was used to test differences between the computed points (i.e., endpoints), except that point values were substituted for betas, and a standard error that corresponds to each test was obtained by following the guidelines recommended by Curran, Bauer, and Willoughby (in press).

All conditional analyses were conducted by systematically entering each main predictor (e.g., Wave 1 anxious solitude, exclusion) and additional control variables (e.g., sex, grade) at each level of the model (intercept and linear slope) and then removing nonsignificant predictors. However, when analyses revealed a significant 
interaction term, main effects were retained in that portion of the model even if they were nonsignificant to allow for accurate interpretation of the interaction in the presence of the main effects. Systematic examination of grade and sex interactions was performed in the continuous analyses. None of the relationships of interest was qualified by grade, and thus final analyses were collapsed across grade. Some significant interactions were found for sex in continuous analyses. In these cases, group analyses were performed with both single- and combined-sex groups. When results of single-sex group analyses differed for boys and girls, results of singlesex group analyses are reported; otherwise, combined-sex analyses are reported.

Initial continuous analyses included an Aggression $\times$ Exclusion interaction term and an Anxious Solitude $\times$ Exclusion interaction term. All interaction terms were computed with centered variables. Because no significant Aggression $\times$ Exclusion interactions emerged, all aggression terms were deleted from continuous analyses. However, aggressive subgroups were retained for group analyses in which different trajectories were found for excluded and nonexcluded aggressive youth.

Groups were formed using joint behavioral (anxious solitude, aggression) and interpersonal (peer exclusion) criteria assessed at Wave 1. Mutually exclusive excluded, anxious solitary-nonexcluded, anxious solitaryexcluded, aggressive-nonexcluded, aggressive-excluded, and anxious solitary-aggressive-excluded groups were formed. The excluded group ( $n=23,35 \%$ female) was $>1 S D$ in exclusion and $<1 S D$ in anxious solitude and aggression. The anxious solitary-nonexcluded group $(n=29,52 \%$ female $)$ was $>1 S D$ in anxious solitude and < $1 S D$ in exclusion and aggression. The anxious solitary-excluded group $(n=27,52 \%$ female) was $>1 S D$ in anxious solitude and exclusion and $<1 S D$ in aggression. The aggressive-nonexcluded group $(n=46,41 \%$ female) was $>1 S D$ in aggression and $<1 S D$ in anxious solitude and exclusion. The aggressive-excluded group $(n=12,42 \%$ female) was $>1 S D$ in aggression and exclusion and $<1 S D$ in anxious solitude. Finally, the anxious solitary-aggressive-excluded group ( $n=16,38 \%$ female) was $>1 S D$ in anxious solitude, aggression, and exclusion.

Girls and boys were equally represented in both anxious solitary-excluded and anxious solitary-nonexcluded groups. Similarly, correlational analysis revealed that there was a similar degree of association between anxious solitude and peer exclusion for girls $(r=.56, p<.001)$ and boys $(r=.53, p<.001)$.

\section{Unconditional Models}

Unconditional analyses indicated that there was significant individual variation relative to the mean trajectory in prosocial behavior, socially helpless behavior, and depressive symptom trajectories (see random effects in Table 2). Each unconditional model indicated that there was significant variation to be accounted for both in the intercept (Wave 1 levels of the dependent variable) and in slope indicating change over time (linear slope of the dependent variable). Next, the hypothesized trajectories were examined by specifying Level 2 between-subjects independent variables (e.g., anxious solitude, exclusion) in conditional analyses.

\section{Prosocial Behavior}

Continuous approach. We hypothesized that anxious solitude would predict low initial levels of prosocial behavior and maintenance or decrease in prosocial behavior over time in the presence of peer exclusion, but increase in prosocial behavior over time in the absence of peer exclusion. As expected, high anxious solitude predicted significantly less prosocial behavior relative to the mean at the Wave 1 assessment. Also consistent with hypotheses, a significant Anxious Solitude $\times$ Exclusion interaction in slope (Table 3) indicated that anxious solitude predicted significantly divergent trajectories of prosocial behavior over time under conditions of high versus low exclusion. Under conditions of high peer exclusion, high anxious solitude predicted the relative maintenance of low prosocial behavior over time, but under conditions of low peer exclusion, high anxious solitude predicted significant linear increase in prosocial behavior over time (the difference between trajectories predicted by high anxious solitude under high versus low exclusion increased from a difference of $.58, t=-5.12, p<.001$, at Wave 1 to a difference of $.79, t=-5.72, p<.001$, at Wave 3; see Table 3 and Figure 1). These results are consistent with the premise that anxious solitary youth maintain low social approach over 
time in the face of interpersonal adversity but shift toward increasing social approach over time in the absence of adversity.

Table 2

Unconditioned Growth Curve Models

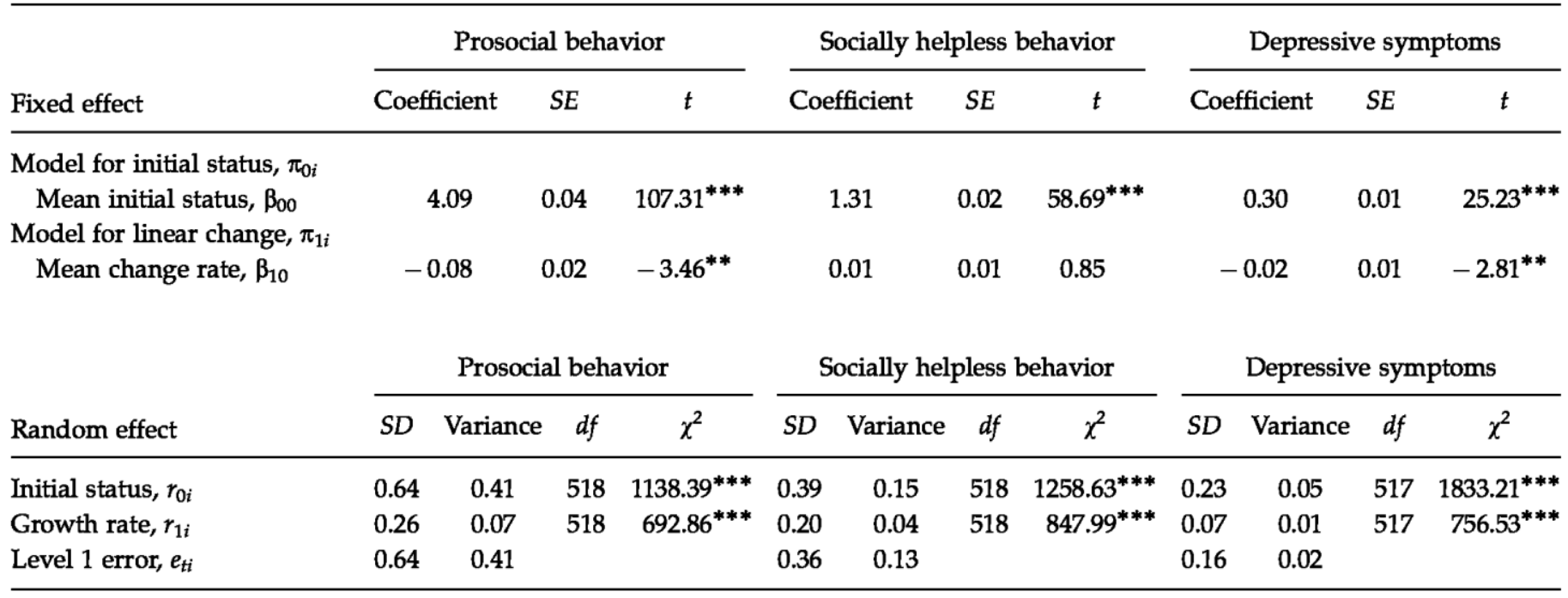

${ }^{* *} p<.01 .{ }^{* * *} p<.001$.

Group approach. Consistent with the results of the continuous analysis, group analysis indicated that anxious solitary-nonexcluded and anxious solitary-excluded youth were significantly less prosocial than the mean at the Wave 1 assessment (and anxious solitary-nonexcluded youth were significantly more prosocial than their anxious solitary-excluded counterparts at Wave $1, .39, t=2.03, p<.05$ ). In support of hypotheses, anxious solitary-excluded youth demonstrated a moderate linear decrease in prosocial behavior parallel to the mean over time, whereas their anxious solitary-nonexcluded counterparts demonstrated a linear increase in prosocial behavior relative to the mean over time (see Table 3 and Figure 2), leading to a larger difference between the two groups at Wave 3, $.65, t=2.00, p<.05$. Again, these results are consistent with the hypothesis that changes in anxious solitary youth's social engagement over time are dependent on the interpersonal environment they encounter.

The prosocial trajectories of aggressive and behaviorally normative youth were also analyzed to examine whether the putative effects of peer exclusion are specific to anxious solitary youth or may affect other youth in similar ways. Similar to the pattern observed in anxious solitary youth, both aggressive-nonexcluded and aggressive-excluded youth were significantly less prosocial than the mean at the Wave 1 assessment (and marginally different from each other, $.41, t=1.95, p<.10)$. Aggressive-excluded youth demonstrated a modest linear decrease in prosocial behavior over time parallel to the mean, whereas aggressive-nonexcluded youth demonstrated a significant linear increase in prosocial behavior over time relative to the mean, leading to a larger difference between the two groups at Wave 3,1.01,t=3.09, $p<.01$. Furthermore, excluded youth with no behavioral risk were significantly less prosocial than the mean at the Wave 1 assessment and demonstrated a modest linear decrease in prosocial behavior over time parallel to the mean. Overall, nonexcluded youth with diverse behavioral orientations became increasingly socially engaged over time in contrast to excluded youth who shared similar behavioral characteristics. Although the anxious solitary-aggressive-excluded group was significantly less prosocial than almost all other youth at Wave $1, t \mathrm{~s}=5.44-7.52, p \mathrm{~s}<.001$, except aggressiveexcluded youth, $t=1.13, n s$, it was an exception to the general pattern of decreasing pro-social behavior among groups of excluded youth. However, this group remained among those with the lowest levels of prosocial behavior at Wave 3 . 


\begin{tabular}{|c|c|c|c|}
\hline \multirow[b]{2}{*}{ Level of model } & \multicolumn{3}{|c|}{ Prosocial behavior } \\
\hline & Coefficient & $S E$ & $t$ \\
\hline \multicolumn{4}{|c|}{ Continuous approach } \\
\hline \multicolumn{4}{|l|}{ Model for initial status, $\pi_{0 i}$} \\
\hline Mean initial status, $\boldsymbol{\beta}_{00}$ & 4.09 & 0.03 & $124.68^{* * *}$ \\
\hline Anxious solitude, $\boldsymbol{\beta}_{01}$ & -0.63 & 0.14 & $-4.57^{* * *}$ \\
\hline Sex, $\beta_{03}$ & -0.17 & 0.03 & $-5.73^{* * *}$ \\
\hline \multicolumn{4}{|l|}{ Model for linear change, $\pi_{1 i}$} \\
\hline Mean change rate, $\beta_{10}$ & -0.06 & 0.02 & $-2.69^{* *}$ \\
\hline Anxious solitude, $\beta_{11}$ & 0.25 & 0.09 & $2.71^{* *}$ \\
\hline Exclusion, $\beta_{12}$ & 0.20 & 0.08 & $2.48^{*}$ \\
\hline Mean initial status, $\boldsymbol{\beta}_{00}$ & 4.37 & 0.03 & $125.04^{* * *}$ \\
\hline Excluded group, $\beta_{01}$ & -0.34 & 0.14 & $-2.42^{*}$ \\
\hline Anxious solitary-nonexcluded group, $\beta_{02}$ & -0.40 & 0.14 & $-2.80^{* *}$ \\
\hline Anxious solitary-excluded group, $\beta_{03}$ & -0.80 & 0.13 & $-6.14^{* * *}$ \\
\hline Aggressive-nonexcluded group, $\beta_{04}$ & -1.16 & 0.10 & $-12.09^{* * *}$ \\
\hline Aggressive-excluded group, $\beta_{05}$ & -1.57 & 0.19 & $-8.31^{* * *}$ \\
\hline Anxious solitary-aggressive-excluded group, $\beta_{06}$ & -1.84 & 0.14 & $-13.05^{* * *}$ \\
\hline Sex, $\beta_{07}$ & -0.17 & 0.03 & $-6.25^{* * *}$ \\
\hline \multicolumn{4}{|l|}{ Model for linear change, $\pi_{1 i}$} \\
\hline Mean change rate, $\beta_{10}$ & -0.12 & 0.03 & $-4.78^{* * *}$ \\
\hline Anxious solitary-nonexcluded group, $\beta_{11}$ & 0.13 & 0.07 & $1.95 \dagger$ \\
\hline
\end{tabular}

$\dagger p<10 .{ }^{*} p<.05 .{ }^{* *} p<.01 .{ }^{* * *} p<.001$.

\section{Socially Helpless Behavior}

Continuous approach. We hypothesized that anxious solitude would predict high initial levels of socially helpless behavior and maintenance, or increase in helpless behavior over time in the presence of peer exclusion, but decrease in helpless behavior over time in the absence of peer exclusion. Because a significant Anxious Solitude $\times$ Exclusion $\times$ Sex interaction $(\beta=.27, t=2.43, p<.05)$ was found for changes in socially helpless behavior over time in the initial continuous analysis, these patterns were subsequently examined separately for boys and girls. For boys, high anxious solitude predicted significantly elevated socially helpless behavior at the Wave 1 assessment. As expected, a significant Anxious Solitude $\times$ Peer Exclusion interaction in slope indicated that anxious solitude predicted significantly divergent trajectories of socially helpless behavior over time under conditions of high versus low exclusion (see Table 4 and Figure 3a). High anxious solitary-high excluded boys demonstrated linearly increasing socially helpless behavior over time, whereas high anxious solitary-low excluded boys demonstrated linearly decreasing socially helpless behavior over time (the difference between these two trajectories increased from .44, $t=4.85, p<.001$, at Wave 1 to $1.01, t=7.56, p<.001$, at Wave 3). These results suggest that anxious solitary boys show increasing social avoidance in the face of interpersonal adversity but decreasing avoidance in the absence of adversity. 


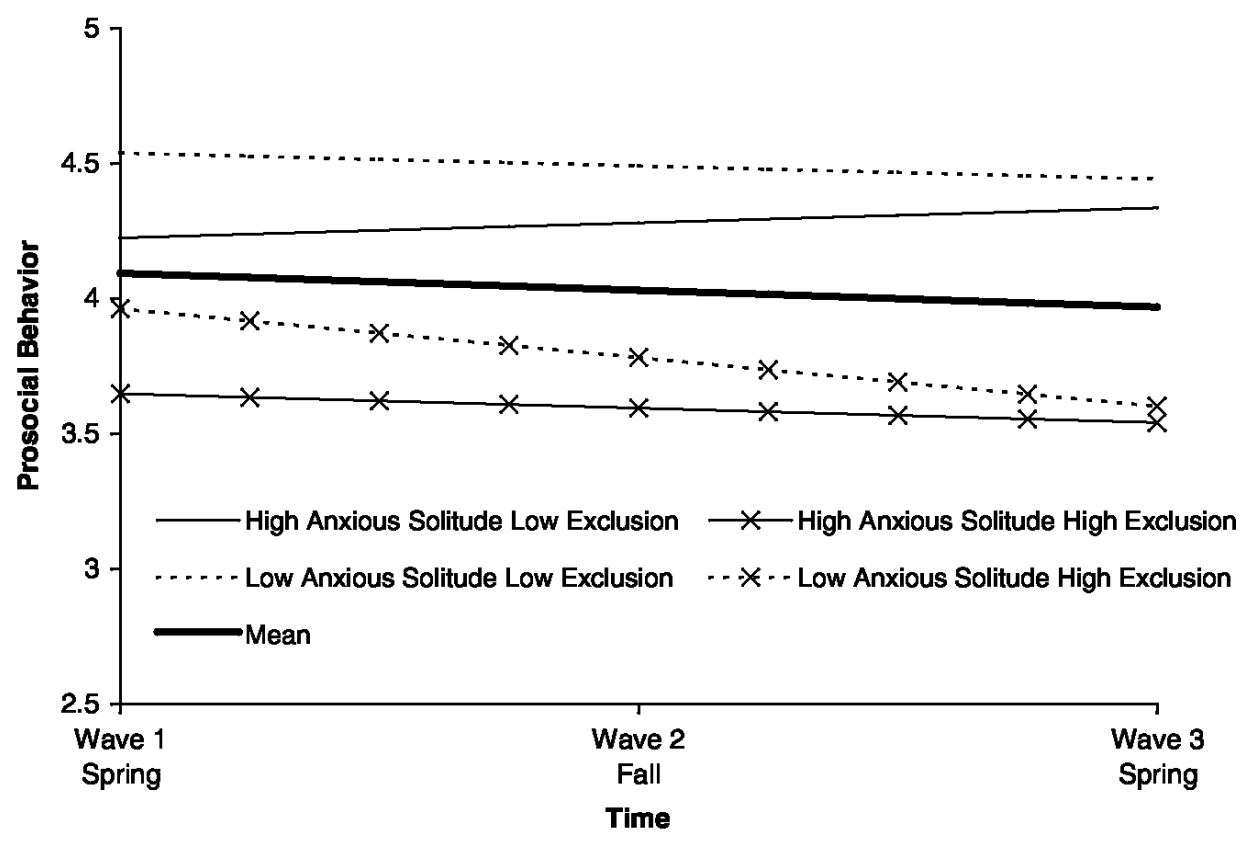

Figure 1. High and low anxious solitude at high and low levels of exclusion predicts prosocial behavior trajectories.

For girls, high anxious solitude predicted significantly elevated socially helpless behavior relative to the mean at Wave 1, and a significant linear decrease in socially helpless behavior relative to the mean over time. High peer exclusion also predicted significantly elevated socially helpless behavior at Wave 1 . Figure $3 \mathrm{~b}$ demonstrates the additive effects of anxious solitude and peer exclusion on girls' socially helpless behavior over time. However, the socially helpless behavior trajectories of high anxious solitary girls under high versus low levels of exclusion did not diverge over time (no significant Anxious Solitude $\times$ Exclusion interaction for slope; Table 4 and Figure 3b).

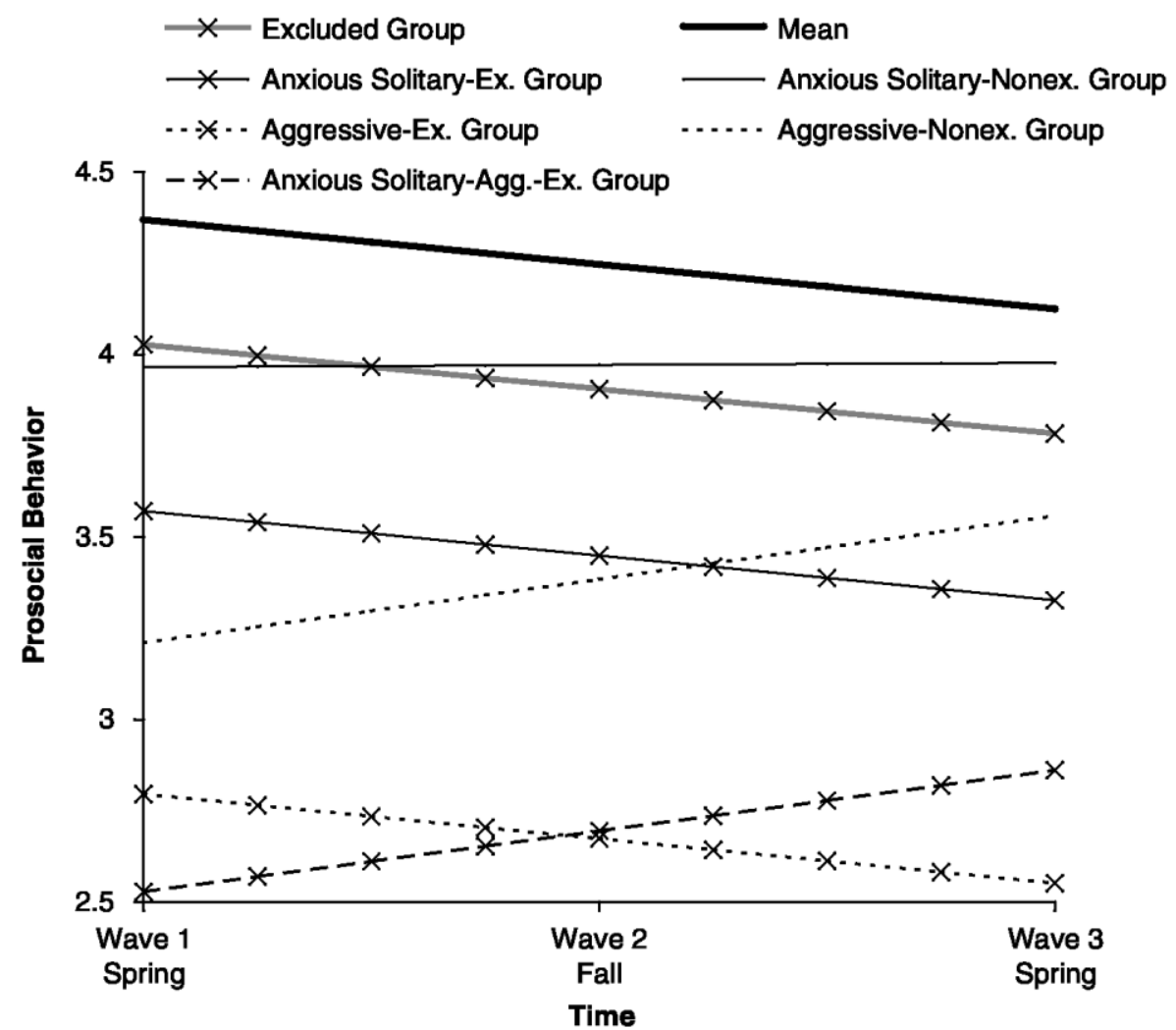

Figure 2. Excluded and nonexcluded behavioral groups predict prosocial behavior trajectories. 


\begin{tabular}{|c|c|c|c|}
\hline \multirow[b]{2}{*}{ Level of model } & \multicolumn{3}{|c|}{ Socially helpless behavior } \\
\hline & Coefficient & $S E$ & $t$ \\
\hline \multicolumn{4}{|c|}{ Continuous approach } \\
\hline \multicolumn{4}{|l|}{ Boys' model for initial status, $\pi_{0 i}$} \\
\hline Mean initial status, $\beta_{00}$ & 1.38 & 0.02 & $56.01^{* * *}$ \\
\hline Anxious solitude, $\beta_{01}$ & 0.88 & 0.14 & $6.28^{* * *}$ \\
\hline Exclusion, $\boldsymbol{\beta}_{02}$ & 0.54 & 0.09 & $5.92^{* * *}$ \\
\hline Grade, $\beta_{03}$ & -0.06 & 0.02 & $-2.48^{* *}$ \\
\hline \multicolumn{4}{|l|}{ Boys' model for linear change, $\pi_{1 i}$} \\
\hline Mean change rate, $\beta_{10}$ & -0.01 & 0.02 & -0.30 \\
\hline Anxious solitude, $\beta_{11}$ & -0.31 & 0.10 & $-2.99^{* * *}$ \\
\hline Exclusion, $\beta_{12}$ & -0.12 & 0.08 & -1.63 \\
\hline Anxious Solitude $x$ Exclusion, $\beta_{13}$ & 0.47 & 0.10 & $4.68^{* * *}$ \\
\hline \multicolumn{4}{|l|}{ Girls' model for initial status, $\pi_{0 i}$} \\
\hline Mean initial status, $\beta_{00}$ & 1.25 & 0.02 & $57.32 * * *$ \\
\hline Anxious solitude, $\beta_{01}$ & 0.74 & 0.14 & $5.14^{* * *}$ \\
\hline Exclusion, $\boldsymbol{\beta}_{02}$ & 0.45 & 0.10 & $4.44^{* * *}$ \\
\hline Grade, $\beta_{03}$ & -0.04 & 0.02 & $-2.05^{*}$ \\
\hline \multicolumn{4}{|l|}{ Girls' model for linear change, $\pi_{1 i}$} \\
\hline Mean change rate, $\beta_{10}$ & 0.00 & 0.02 & 0.22 \\
\hline Anxious solitude, $\beta_{11}$ & -0.39 & 0.10 & $-3.83^{* * *}$ \\
\hline \multicolumn{4}{|c|}{ Group approach } \\
\hline \multicolumn{4}{|l|}{ Model for initial status, $\pi_{0 i}$} \\
\hline Mean initial status, $\boldsymbol{\beta}_{00}$ & 1.13 & 0.01 & $78.02^{* * *}$ \\
\hline Excluded group, $\beta_{01}$ & 0.24 & 0.07 & $3.64^{* * *}$ \\
\hline Anxious solitary-nonexcluded group, $\beta_{02}$ & 0.40 & 0.09 & $4.36^{* * *}$ \\
\hline Anxious solitary-excluded group, $\beta_{03}$ & 0.73 & 0.11 & $6.41^{* * *}$ \\
\hline Aggressive-nonexcluded group, $\beta_{04}$ & 0.47 & 0.08 & $5.88^{* * *}$ \\
\hline Aggressive-excluded group, $\beta_{05}$ & 0.79 & 0.15 & $5.14^{* * *}$ \\
\hline Anxious solitary-aggressive-excluded group, $\beta_{06}$ & 1.52 & 0.17 & $8.80^{* * *}$ \\
\hline Sex, $\beta_{07}$ & 0.05 & 0.02 & $3.32^{* * *}$ \\
\hline \multicolumn{4}{|l|}{ Model for linear change, $\pi_{1 i}$} \\
\hline Mean change rate, $\beta_{10}$ & 0.05 & 0.01 & $3.44^{* * *}$ \\
\hline Anxious solitary-nonexcluded group, $\beta_{11}$ & -0.16 & 0.05 & $-3.07^{* *}$ \\
\hline Aggressive-nonexcluded group, $\beta_{12}$ & -0.17 & 0.06 & $-2.80^{* *}$ \\
\hline Anxious solitary-aggressive-excluded group, $\beta_{13}$ & -0.41 & 0.12 & $-3.44^{* * *}$ \\
\hline
\end{tabular}

${ }^{*} p<.05 .{ }^{* *} p<.01 .{ }^{* * *} p<.001$.

Group approach. Because continuous analyses yielded a significant interaction involving sex, group analyses were performed for both single-sex and combined-sex groups. The results of single-sex analyses were consistent with combined-sex analyses, with girls' and boys' anxious solitary-excluded groups demonstrating more elevated socially helpless behavior over time than nonexcluded same-sex anxious solitary groups. Therefore, only results from combined-sex analyses are reported.

Consistent with expectations, both anxious solitary groups were significantly more socially helpless than the mean at the Wave 1 assessment (and significantly different from each other, $.32, t=2.20, p<.05$ ). As hypothesized, the anxious solitary-excluded group demonstrated a modest linear increase in socially helpless behavior over time parallel to the mean, whereas the anxious solitary-nonexcluded group demonstrated a significant linear decrease in socially helpless behavior relative to the mean over time (see Table 4 and Figure $4)$, leading to a larger difference between the two groups at Wave $3(.48, t=1.96, p<.05)$. These results once again support the premise that changes in anxious solitary youths' social avoidance over time are dependent on the interpersonal environment they encounter. Although continuous analyses revealed some sex differences, 
extreme anxious solitary groups of both sexes demonstrated similarly diverging trajectories of socially helpless behavior under conditions of high versus low exclusion.

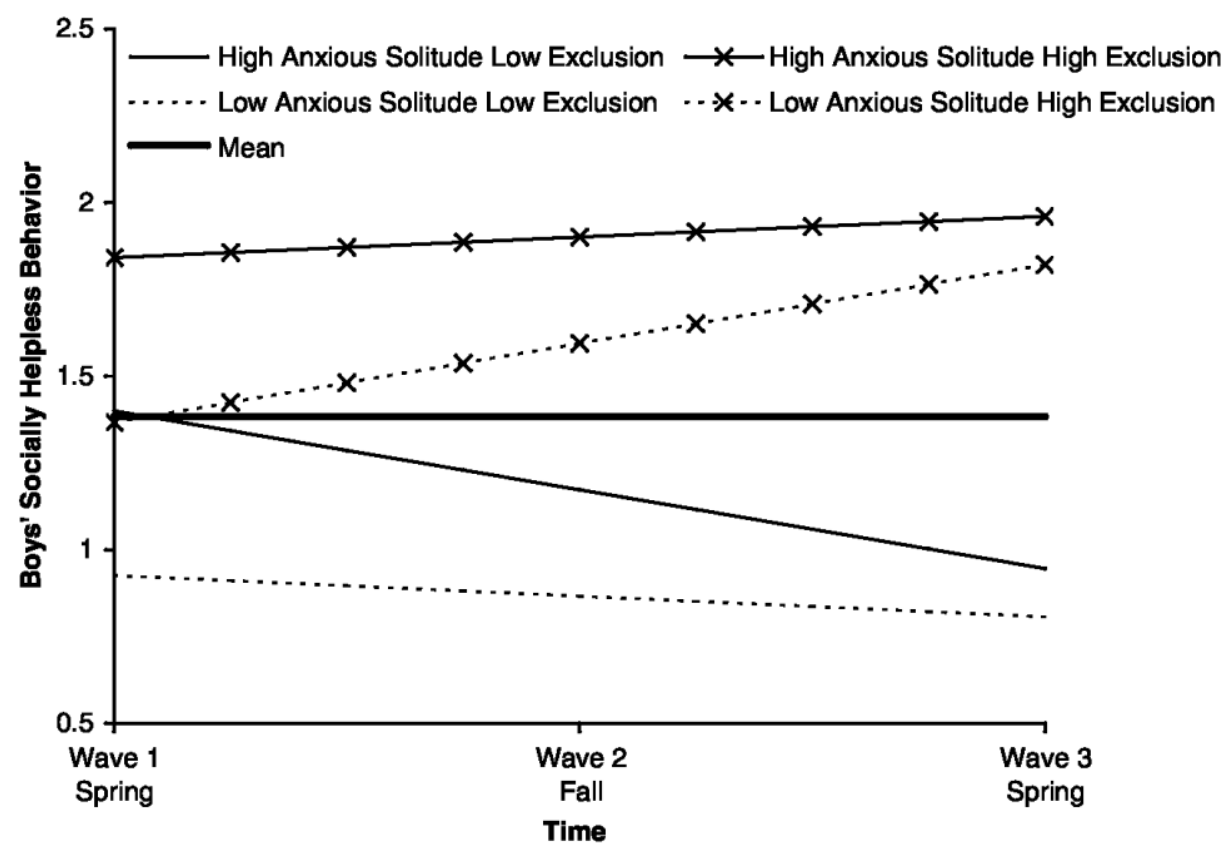

Figure 3a. Boys' high and low anxious solitude at high and low levels of exclusion predicts socially helpless behavior trajectories.

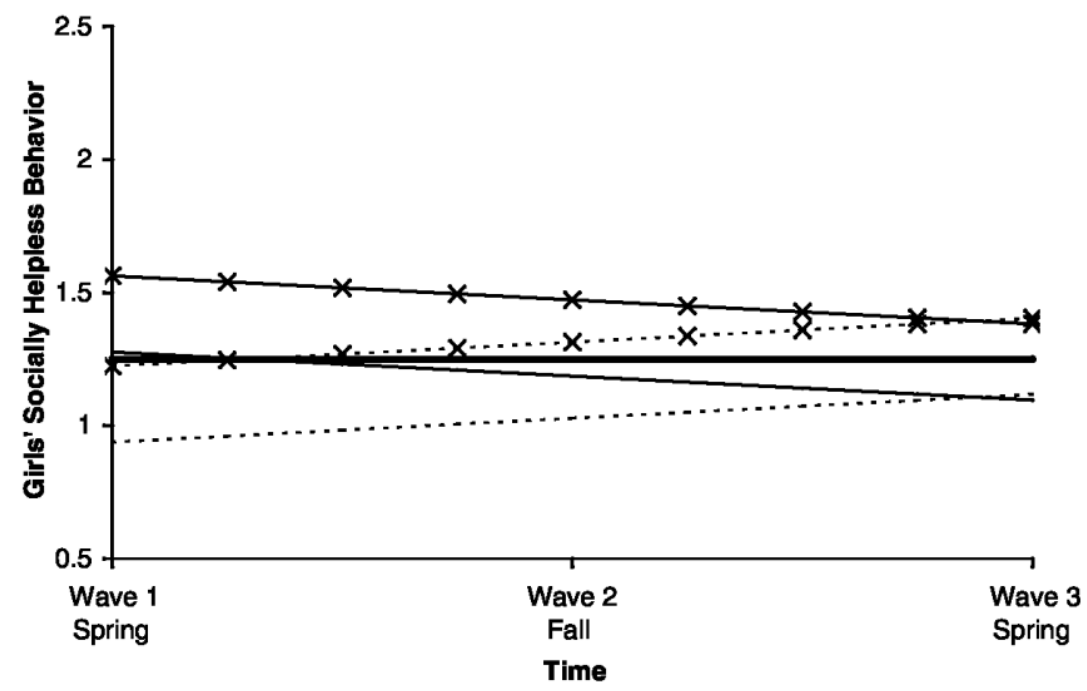

Figure 3b. Girls' high and low anxious solitude and high and low exclusion predict socially helpless behavior trajectories. The trajectories of high- and low-excluded girls at the same level of anxious solitude do not diverge over time.

Trajectories of socially helpless behavior in aggressive and behaviorally normative youth were also examined to determine the specificity of the findings to anxious solitary youth. Aggressive-non-excluded and aggressiveexcluded youth demonstrated significantly elevated socially helpless behavior relative to the mean at Wave 1 (and marginally different from each other, .32, $t=1.85, p<.10$ ). Similar to the patterns observed in anxious solitary groups, aggressive-excluded youth demonstrated a modest linear increase in socially helpless behavior over time parallel to the mean trajectory, whereas aggressive-nonexcluded youth demonstrated a significant 
linear decrease in socially helpless behavior over time relative to the mean trajectory (see Table 4 and Figure 4), leading to a larger difference between the two groups at Wave $3, .67, t=3.11, p<.01$. Excluded youth with no behavioral risk also demonstrated a mild but significant elevation in socially helpless behavior relative to the mean at Wave 1 and a modest linear increase in socially helpless behavior parallel to the mean over time.

Overall, results suggest that the presence of peer exclusion may maintain socially helpless behavior over time in extreme groups of youth with multiple behavioral profiles, whereas the absence of peer exclusion may permit improvement in their same-behavior counterparts. The anxious solitary-aggressive-excluded group showed the most elevated socially helpless behavior of all youth at Wave $1, t \mathrm{~s}=53.84-9.11, p \mathrm{~s}<.001$. This group remained among those with the highest levels of helpless behavior at Wave 3 despite a significant linear decrease relative to the mean over time.

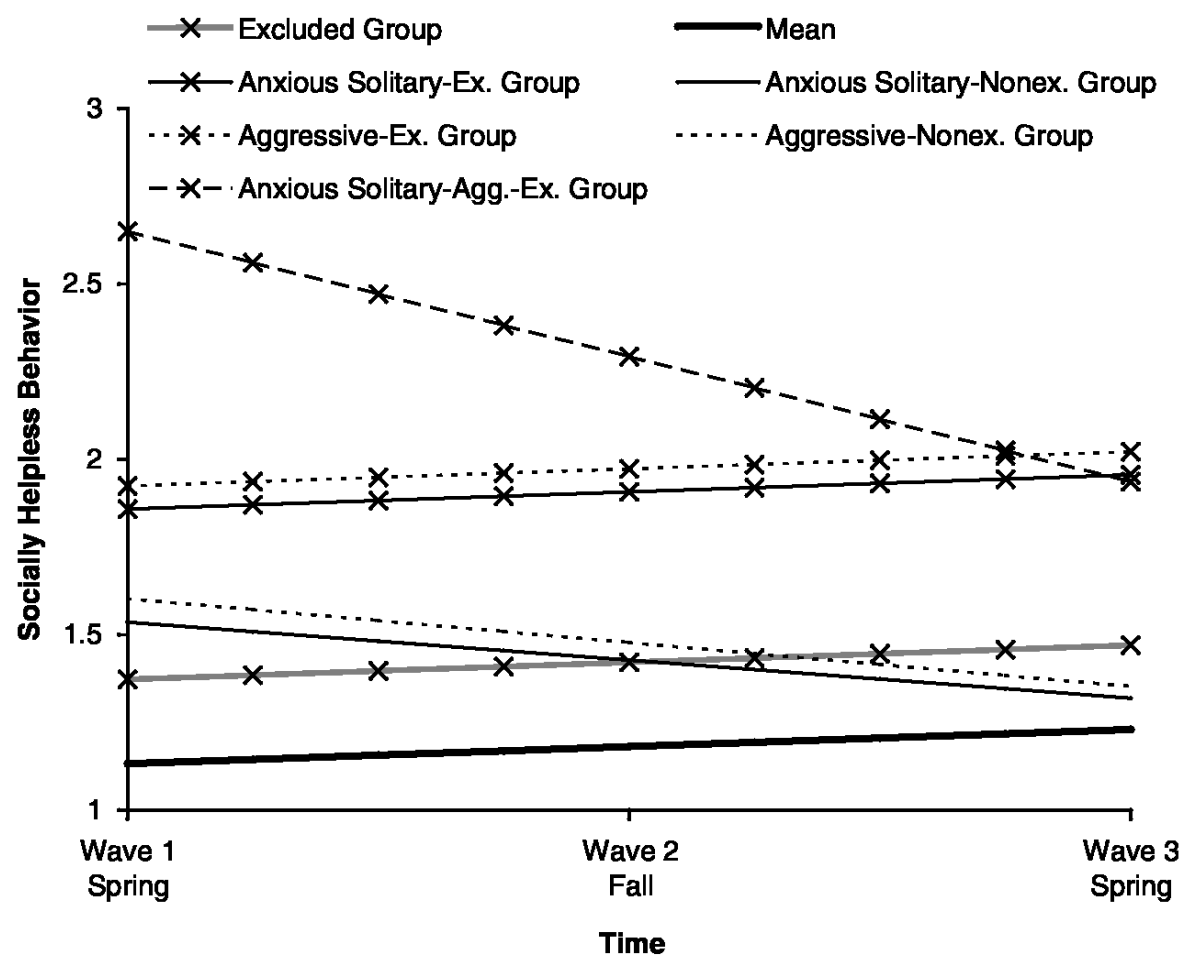

Figure 4. Excluded and nonexcluded behavioral groups predict socially helpless behavior trajectories.

\section{Depressive Symptoms}

Continuous approach. We hypothesized that anxious solitude would predict high initial levels of depressive symptoms, and maintenance or increase in depression over time in the presence of peer exclusion, but decrease in depression over time in the absence of peer exclusion. Because a significant Anxious Solitude $\times$ Exclusion $\times$ Sex interaction $(\beta=.09, t=2.18, p<.05)$ was found for changes in depressive symptoms over time in initial continuous analyses, these patterns were subsequently examined separately for boys and girls.

For boys, high anxious solitude predicted elevated depressive symptoms at Wave 1 assessment. Consistent with the diathesis-stress hypothesis, an Anxious Solitude $\times$ Peer Exclusion interaction in slope indicated that anxious solitude predicted divergent trajectories of depressive symptoms over time under conditions of high versus low exclusion (see Table 5 and Figure 5a). High anxious solitary-high excluded boys demonstrated linearly increasing levels of symptoms, whereas high anxious solitary-low excluded boys demonstrated linearly decreasing levels of symptoms (the difference between these trajectories increased from no difference at Wave 1 to $.11, t=2.42, p<.05$, at Wave 3 ).

For girls, high anxious solitude predicted elevated depressive symptoms at Wave 1 and a significant linear decrease in depressive symptoms relative to the mean over time. High peer exclusion also predicted 
significantly elevated depressive symptoms at Wave 1 . Figure $5 \mathrm{~b}$ demonstrates the additive effects of anxious solitude and peer exclusion on girls' depressive symptoms over time. Anxious solitary girls' depressive symptom trajectories did not diverge over time under conditions of high versus low exclusion (there was no significant Anxious Solitude $\times$ Exclusion interaction for linear change in girls; see Table 5 and Figure 5b).

\begin{tabular}{|c|c|c|c|}
\hline \multirow[b]{2}{*}{ Level of model } & \multicolumn{3}{|c|}{ Depressive symptoms } \\
\hline & Coefficient & $S E$ & $t$ \\
\hline \multicolumn{4}{|c|}{ Continuous approach } \\
\hline \multicolumn{4}{|l|}{ Boys' model for initial status, $\pi_{0 i}$} \\
\hline Mean initial status, $\beta_{00}$ & 0.30 & 0.02 & $19.18^{* * *}$ \\
\hline Anxious solitude, $\beta_{01}$ & 0.19 & 0.07 & $2.72^{* *}$ \\
\hline \multicolumn{4}{|l|}{ Boys' model for linear change, $\pi_{1 i}$} \\
\hline Mean change rate, $\beta_{10}$ & -0.02 & 0.01 & $-2.02^{*}$ \\
\hline Anxious solitude, $\beta_{11}$ & 0.01 & 0.05 & 0.31 \\
\hline Exclusion, $\beta_{12}$ & -0.02 & 0.02 & -0.77 \\
\hline Anxious Solitude $\times$ Exclusion, $\beta_{13}$ & 0.08 & 0.04 & $2.14^{*}$ \\
\hline \multicolumn{4}{|l|}{ Girls' model for initial status, $\pi_{0 i}$} \\
\hline Mean initial status, $\beta_{00}$ & 0.29 & 0.02 & $17.99^{* * *}$ \\
\hline Anxious solitude, $\beta_{01}$ & 0.16 & 0.08 & $1.94 \dagger$ \\
\hline Exclusion, $\beta_{02}$ & 0.22 & 0.06 & $3.95^{* * *}$ \\
\hline \multicolumn{4}{|l|}{ Girls' model for linear change, $\pi_{1 i}$} \\
\hline Mean change rate, $\beta_{10}$ & -0.02 & 0.01 & $-2.50^{*}$ \\
\hline Anxious solitude, $\beta_{11}$ & -0.15 & 0.03 & $-4.26^{* * *}$ \\
\hline \multicolumn{4}{|c|}{ Group approach } \\
\hline \multicolumn{4}{|l|}{ Model for initial status, $\pi_{0 i}$} \\
\hline Mean initial status, $\beta_{00}$ & 0.28 & 0.01 & $24.90^{* * *}$ \\
\hline Girls' anxious solitary-excluded group, $\beta_{01}$ & 0.21 & 0.08 & $2.47^{*}$ \\
\hline Anxious solitary-aggressive-excluded group, $\beta_{02}$ & 0.20 & 0.08 & $2.58^{* *}$ \\
\hline \multicolumn{4}{|l|}{ Model for linear change, $\pi_{1 i}$} \\
\hline Mean change rate, $\beta_{10}$ & -0.02 & 0.01 & $-3.17^{* *}$ \\
\hline Boys' anxious solitary-excluded group, $\beta_{11}$ & 0.10 & 0.03 & $2.84^{* *}$ \\
\hline
\end{tabular}

Group approach. Because the continuous analyses yielded a sex difference in the interaction of anxious solitude and exclusion, group analyses were performed with both single-sex and combined-sex groups. Combined-sex analyses indicated that anxious solitary-excluded youth reported more depressive symptoms over time than did their nonexcluded counterparts. However, single-sex analyses illustrated somewhat different timing in the emergence of depressive symptoms in anxious solitary-excluded boys versus girls. Therefore, results of singlesex group analyses are reported.

Anxious solitary-excluded girls reported significantly elevated depressive symptoms relative to the mean at the Wave 1 assessment and maintained this relative elevation over time parallel to the slight linear decrease in the mean trajectory. Anxious solitary-excluded boys did not report significantly more depressive symptoms relative to the mean at the Wave 1 assessment but demonstrated a significant linear increase in reported depressive symptoms over time relative to the mean trajectory (see Table 5 and Figure 6), leading to significantly elevated depressive symptoms relative to the mean at Wave $3, .19, t=4.02, p<.001$, and no significant difference between anxious solitary-excluded boys and girls at Wave 3, .02, $t=0.14, n s$. In contrast, the depressive symptom trajectories of anxious solitary-non-excluded youth of both sexes did not differ significantly from the mean trajectory (and thus are not shown in Figure 6). Overall, anxious solitary-excluded youth of both sexes reported elevated depressive symptoms, but elevation appeared earlier for girls than boys. 
To examine specificity of the effects of exclusion, the depressive symptom trajectories of aggressivenonexcluded, aggressive-excluded, and excluded youth also were examined. The depressive symptom trajectories of these groups did not deviate significantly from the mean. However, the anxious solitaryaggressive-excluded group reported significantly elevated depressive symptoms at the Wave 1 assessment and relative maintenance over time parallel to the slightly decreasing mean trajectory (this group's trajectory is not depicted in Figure 6 because it lies almost on top of the trajectory for anxious solitary-excluded girls).

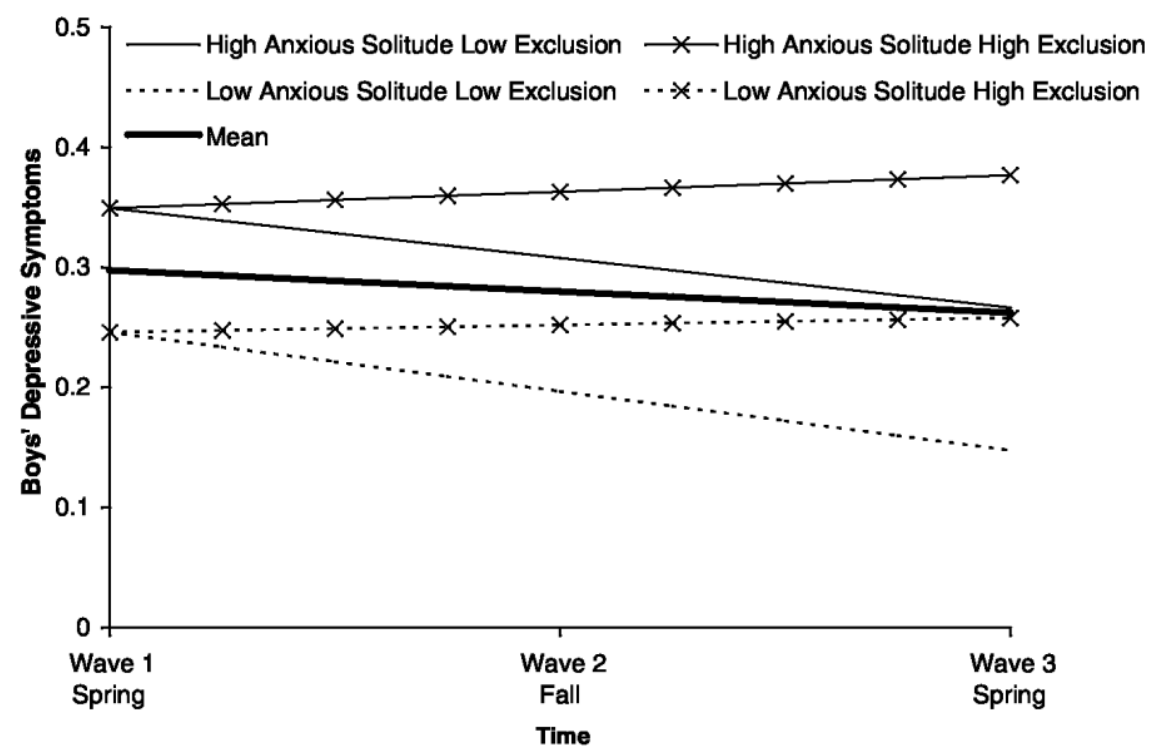

Figure 5a. Boys' high and low anxious solitude at high and low levels of peer exclusion predicts self-reported depressive symptom trajectories.

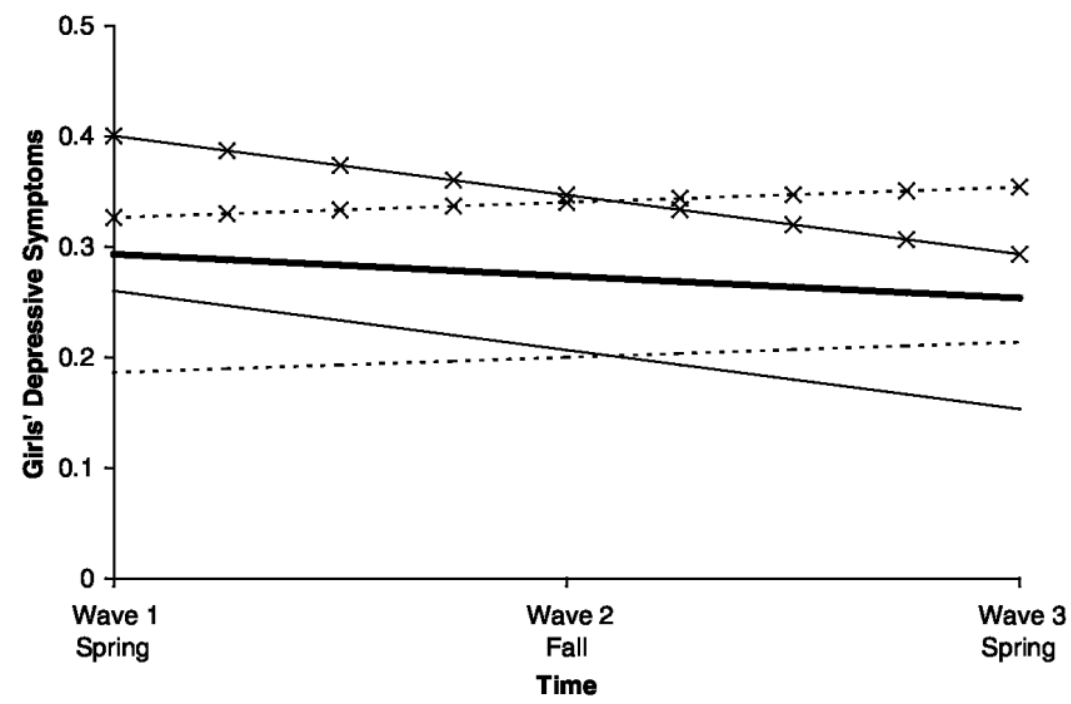

Figure $5 b$. Girls' high and low anxious solitude and high and low exclusion predict self-reported depressive symptom trajectories. The trajectories of high- and low-excluded girls at the same level of anxious solitude do not diverge over time.

\section{Analyses Controlling for Initial Differences}

Because initial differences were found in the prosocial and socially helpless behavior of excluded versus nonexcluded same-behavior youth, an additional version of all growth-curve analyses was conducted controlling for these initial differences. In each analysis, all previous findings remained significant. 


\section{Discussion}

The present findings support a person-by-environment model of development (Magnusson, 1988), emphasizing the dynamic interplay between individuals and their interpersonal environments in shaping adjustment over time. Results suggest that individual vulnerability (anxious solitude) forecasts divergent developmental pathways in the presence versus absence of interpersonal adversity (peer exclusion) during early adolescence. Vulnerable youth appeared to continue in their movement away from their peer worlds in the presence of interpersonal adversity but to show increasing engagement with their peer worlds in the absence of interpersonal adversity.

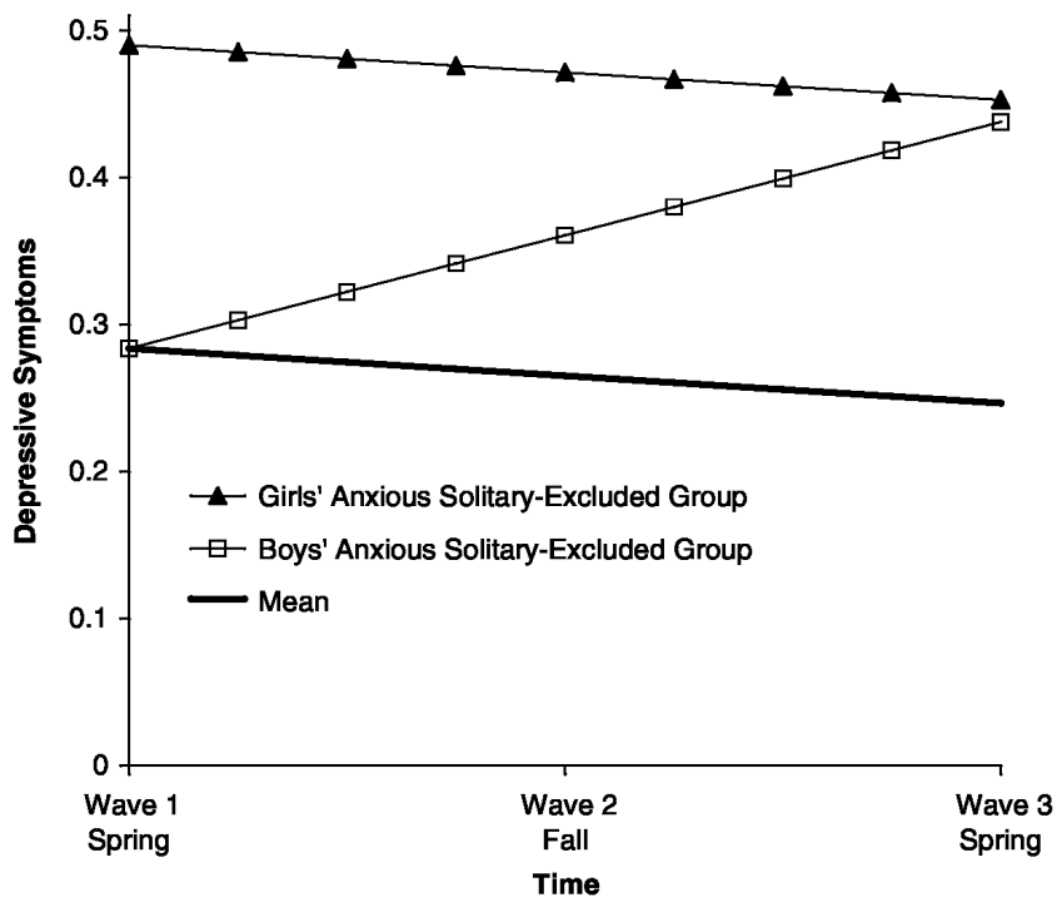

Figure 6. Girls' and boys' anxious solitary-excluded groups predict self-reported depressive symptom trajectories. Other groups are not shown because they did not differ significantly from the mean trajectory, or in the case of the anxious solitary-aggressive-excluded group, because the trajectory overlays that of the girls' anxious solitary-excluded group.

Prior research has demonstrated that anxious solitude and peer exclusion co-occur in many youth and are mutually reinforcing over the course of childhood (Gazelle \& Ladd, 2003). The present research substantially furthers this knowledge by demonstrating that (a) anxious solitude and exclusion jointly contribute to change in youth's social approach and avoidance behaviors in ways that are consistent with theories of motivation, (b) nonthreatening peer environments may redirect the trajectories of some vulnerable youth into more healthy directions, (c) the effects of peer exclusion appear particularly pervasive in anxious solitary youth, and (d) sex differences in the concomitants of anxious solitude may change across periods of development. This knowledge provides a more comprehensive conceptual framework for understanding risk and resilience in anxious solitary youth.

\section{Social Approach and Avoidance Trajectories and Theories of Motivation}

Findings revealed that, in the absence of peer exclusion, anxious solitary youth's behavior shifted toward more social approach (prosocial behavior) and less social avoidance (socially helpless behavior) over time. These findings are consistent with Asendorpf's (1990) motivational theory of anxious solitude, which suggests that anxious solitary behavior results from the conflicting forces of high social avoidance motivation and normative levels of social approach motivation. If an anxious solitary individual experiences a decrease in social avoidance motivation, social approach motivation would no longer be held in check, resulting in increased social approach behaviors. Why might anxious-nonexcluded youth experience a decrease in avoidance motivation? Typically, anxious individuals' fears persist because they avoid feared situations and, consequently, 
the opportunity to have fear-disconfirming experiences. However, most anxious solitary youth are not permitted to elect themselves out of all peer interactions, as they are required to attend school, and consequently they experience at least a minimum of social interaction. If anxious solitary youth are not excluded by peers, their fears may be disconfirmed, thereby reducing their fear-based social avoidance motivation. Inclusion by peers also may influence other motivational factors, such as enhancing self-efficacy beliefs and modifying attributions about social success and failure.

Conversely, in the presence of peer exclusion, anxious solitary youth demonstrated relative maintenance or increase in social avoidance over time. When anxious solitary youth encounter peer mistreatment, their social fears and low perceived self-efficacy may be confirmed, further undermining efforts toward social engagement. Present findings therefore provide information about change in anxious solitary youth's approach and avoidance behaviors under varying levels of interpersonal adversity that is not only novel but also consistent with theoretical perspectives on approach and avoidance motivation (Asendorpf, 1990) and more general motivational theories of learned helplessness (Dweck \& Leggett, 1988) and self-efficacy (Bandura, 1988/1991). Although present findings are consistent with motivational theories at a behavioral level, important directions for future research are direct measurement of motivational orientations in anxious solitary youth, and investigation of interpersonal circumstances that shape motivation over time.

\section{Diathesis Stress and Depression}

The present results support a diathesis-stress model of depression, which hypothesizes that individual vulnerability in the form of anxious solitude is activated in the face of interpersonal adversity (Gazelle \& Ladd, 2003). In group analyses, anxious solitary-excluded youth of both sexes reported elevated depressive symptoms over time. In contrast, youth who encountered only one of these risks (anxious solitude or exclusion) did not report elevated depressive symptoms over time. Continuous analyses similarly indicated that the most elevated depressive symptoms resulted from the joint influence of high anxious solitude and high peer exclusion. However, in boys these effects were interactive and led to divergent trajectories of depressive symptoms, but in girls these effects were additive and led to stable differences in depressive symptoms over time.

The overall pattern of findings is consistent with the idea that interpersonal adversity may trigger the transformation of helplessness associated with anxiety into hopelessness characteristic of depression through confirmation of anxious individuals' fears (see Alloy et al., 1990). In the context of exclusion, worry about how one is likely to be received by social partners may be supplemented with certainty that one will be mistreated and a sense of powerlessness to change this situation.

\section{Specificity}

The present study extends prior research by its investigation of whether the adaptational significance of peer exclusion is of particular salience in anxious solitary youth or similar in all youth. Continuous analyses revealed Anxious Solitude $\times$ Peer Exclusion interactions (sometimes qualified by sex) for all three outcomes, whereas no Aggression $\times$ Peer Exclusion interactions emerged as statistically significant. In contrast, group analyses suggested that extremely excluded youth with multiple behavioral profiles (aggressive and behaviorally normative, as well as anxious solitary) exhibited elevated and more stable social disengagement over time. Nevertheless, only the combination of anxious solitude and exclusion (with or without additional aggression) predicted youth's self-reported depressive symptoms. Taken together, it appears that anxious solitary youth may be especially sensitive to peer exclusion because the Anxious Solitude $\times$ Exclusion effect was particularly consistent across different analytic approaches, developmental outcomes (prosocial behavior, helpless social behavior, and depressive symptoms), and informants (teacher and self).

Why might continuous and group results be consistent for anxious solitude but discrepant for aggression? Anxious solitude and exclusion may interact at extreme as well as more intermediate levels on a continuum, whereas the interaction between aggression and exclusion may occur only at extreme levels. The appearance of an exclusion moderation effect only among extremely aggressive youth raises the possibility that youth in this 
group differ from their more moderately aggressive counterparts in quality of individual vulnerability rather than only in quantity of the same vulnerability. Qualitative differences in the developmental histories (e.g., presence of family violence) of extremely versus more moderately aggressive youth may yield a group of extremely aggressive youth who are particularly sensitive to interpersonal stress.

Evidence of specificity also occurred in the depression findings. Excluded and aggressive-excluded groups of youth displayed social disengagement but not depressive symptoms, whereas anxious-excluded youth displayed both social disengagement and depressive symptoms. Peer mistreatment may influence the social-behavioral engagement of youth with diverse behavioral orientations because it is proximal to their social behavior, but it may not influence more distal emotional functioning in youth without a particular vulnerability to depression (i.e., anxiety).

Consistent with findings from multiple investigations (e.g., Gazelle \& Ladd, 2003; Ladd \& Burgess, 1999; Ledingham \& Schwartzman, 1984; Ledingham, Schwartzman, \& Serbin, 1984; Serbin et al., 1998), anxious solitary-aggressive youth exhibited the most severe maladjustment. These youth were highly excluded at the outset of the study and were among those who displayed the highest levels of social disengagement throughout the study, although they were the only excluded group who demonstrated a decrease in social disengagement over time. Because this group demonstrated such extreme social disengagement at the outset of the study, this decrease may have resulted from regression toward the mean. On balance, present results concur with previous findings indicating that anxious solitary-aggressive youth demonstrate particularly extreme adjustment difficulties.

\section{Sex Differences}

Several interesting sex differences emerged in adjustment trajectories over time. Although anxious solitude and exclusion consistently predicted adjustment difficulties for both sexes, the joint influence of these factors predicted divergent adjustment trajectories more consistently for boys. This pattern may in part reflect the potent contributions of anxious solitude and exclusion to elevation in girls' maladjustment at the outset of the study and limited ability to predict incremental change beyond already elevated levels. For example, continuous analyses revealed that high anxious solitude in the context of high exclusion predicted more elevated depressive symptoms in girls relative to boys at Wave 1. Group analyses further suggested that anxious solitary-excluded girls reported initial and relatively sustained elevation in depressive symptoms over time, whereas their male counterparts showed no initial elevation but a subsequent increase in depressive symptoms over time.

These findings contrast with those from prior studies, which suggest more negative adjustment in anxious solitary boys than girls (e.g., Coplan et al., 2001; Gazelle \& Ladd, 2003). This contrasting pattern may result from differences in the impact of anxious solitude at different developmental stages. Whereas anxious solitary boys may encounter more exclusion during middle childhood, exclusion may be equally prevalent for both sexes and particularly pernicious to the emotional adjustment of anxious solitary girls during early adolescence, when girls highly value peer relationships. Girls may react more quickly to exclusion at this time because they are particularly concerned about interpersonal belonging and adversity (Maccoby, 1990; Rudolph, 2002).

\section{Continuous and Group-Oriented Analyses as Complementary}

Our investigation was enhanced by the complementary perspectives gained through continuous and categorical analytic lenses. The continuous approach was well suited for investigating the statistical interaction implied by a person-by-environment model of development. However, important arguments have been made for studying anxious solitary youth as an extreme group (Rubin, 1993). We anticipated that complementary continuous and categorical results would bolster confidence in findings. Indeed, this dual analytic approach offered benefits beyond those we could have foreseen. The continuous approach was uniquely effective in describing sex differences in trajectories of social helplessness. The categorical approach uniquely elucidated sex differences in timing of depressive symptoms in anxious solitary-excluded youth and revealed that exclusion predicted change in social engagement for extremely aggressive youth. This important parallel between the putative 
effects of exclusion on the engagement trajectories of behaviorally diverse youth would have been overlooked had we taken an exclusively continuous approach.

\section{Risk for Peer Exclusion}

Because peer exclusion, as an index of the peer world's orientation toward a youth, appears to play an important role in whether behaviorally vulnerable youth show improvements or continued problems with social engagement and emotional functioning over time, the present findings raise the question of which behaviorally vulnerable youth are at risk for peer exclusion. More specifically, is differential risk located within the individual or environment level, or at the intersection of these levels?

In past investigations, sex has been the individual-level factor that best differentiates anxious solitary children who later show social difficulties from those who do not, with boys demonstrating greater risk of peer exclusion and rejection and other social difficulties (Caspi et al., 1988; Coplan et al., 2001; Gazelle \& Ladd, 2003; Morison \& Masten, 1991; Rubin et al., 1993; Stevenson-Hinde \& Glover, 1996). However, in the present study, early adolescent boys and girls were equally represented among same-behavior youth who were excluded versus nonexcluded. It may be that the hierarchical nature of boys' peer interactions demands social initiative from an early age, resulting in higher rates of peer exclusion of anxious solitary boys in middle childhood, whereas successful peer interactions in early adolescence may demand social initiative from both sexes.

Beyond sex, other individual attributes may contribute to differential risk for exclusion. For example, shyinhibited children who show high IQ and teacher-reported social competence tend to have more adaptive developmental outcomes (Asendorpf, 1994). Such youth also may be less at risk for peer exclusion. In the present study, differences in initial levels of prosocial and socially helpless behavior were found between excluded and nonexcluded anxious solitary youth. It is unclear whether these differences preceded or resulted from exclusion, but divergent adjustment trajectories remained significant after adjusting for these initial differences. However, it is possible that anxious solitary youth who are excluded differ from those who are not excluded in other important ways beyond their social behavior. Such potential differences may contribute both to youth's exclusion and to their adverse developmental trajectories. It will therefore be important in future research to determine whether exclusion contributes independently to future adjustment or reflects a marker of a broader group of risk factors for certain anxious solitary youth.

Regardless of whether the attributes of some anxious solitary youth contribute to their exposure to peer exclusion, once this exclusion occurs it becomes a potent aspect of the social environment with which youth must cope. Indeed, several prominent developmental perspectives emphasize that social environments exert a reciprocal influence on subsequent development even though youth select and create their social environments to some degree (Caspi et al., 1988; Egan \& Perry, 1998; Rudolph \& Hammen, 1999; Scarr, 1992). Thus, peer exclusion can be seen as a construct that is located at the intersection of individuals and their peer environments. Additionally, it is important to consider the broader environmental context of exclusion. At a proximal level, anxious solitary youth who have close friendships may be less excluded than those who are friendless (see Hodges, Malone, \& Perry, 1997, for evidence related to victimization). More broadly, certain classroom or school contexts may be less conducive to peer exclusion than others. Rules such as "you can't say you can't play" are part of the fabric of some classroom and school cultures (Paley, 1992), whereas such explicit guiding philosophies against peer exclusion appear to be absent from others. Measurement of such multilayered environmental effects is an important direction for future research on the transactional nature of youth's individual vulnerabilities and interpersonal risks.

\section{Implications for Intervention}

Present findings suggest that intervention efforts for vulnerable youth should target both the environmental level (e.g., tolerance for exclusion at school) and the individual level (e.g., regulation of social anxiety). School-based victimization prevention programs recently have received increased attention within the United States after a critical mass of highly publicized incidents of peer violence and suicides related to victimization at school. However, it is important that such programs target not only acts that physically victimize but also more 
pervasive and subtle acts of exclusion that appear to undermine students' social engagement and may contribute to feelings of alienation from school.

\section{Conclusion}

This investigation provided support for a person-by-environment model (Magnusson, 1988) that emphasizes dynamic interactions between individuals and their environments over time using growth-curve analyses that enable tracking of individual longitudinal trajectories. Findings demonstrate that continuity and change in youth's adjustment may be due in part to the nature of their interpersonal environment. Youth with a tendency to move away from the world maintained this behavioral trajectory over time when the world also moved away from them. However, the orientation of the environment toward youth also appeared to hold potential for positive influence: When the world did not move away from youth, they appeared to shift toward the world.

\section{References:}

Abramson, L. Y., Alloy, L. B., \& Metalsky, G. I. (1988). The cognitive diathesis-stress theories of depression: Toward an adequate evaluation of the theories' validities. In L. B. Alloy (Ed.), Cognitive processes in depression (pp. 3-30). New York: Guilford Press.

Achenbach, T. (1991). Manual for the Teacher's Report Form and 1991 Profile. Burlington: University of Vermont, Department of Psychiatry.

Alloy, L. B., Hartlage, S., \& Abramson, L. Y. (1988). Testing the cognitive diathesis-stress theories of depression: Issues of research design, conceptualization, and assessment. In L. B. Alloy (Ed.), Cognitive processes in depression (pp. 31 - 73). New York: Guilford Press.

Alloy, L. B., Kelly, K. A., Mineka, S., \& Clements, C. M. (1990). Comorbidity of anxiety and depressive disorders: A helplessness-hopelessness perspective. In J. D. Maser \& C. R. Cloninger (Eds.), Comorbidity of mood and anxiety disorders (pp. 499-543). Washington, DC: American Psychiatric Press.

Asendorpf, J. B. (1990). Beyond social withdrawal: Shyness, unsociability, and peer avoidance. Human Development, 33, $250-259$.

Asendorpf, J. B. (1994). The malleability of behavior inhibition: A study of individual developmental functions. Developmental Psychology, 30, 912-919.

Bandura, A. (1988). Self-efficacy conception of anxiety. Anxiety Research, 1, 77-98. (Reprinted in Anxiety and self-focused attention, pp. 89-110, by R. Schwarzer \& R. A. Wicklund, Eds., 1991, New York: Harwood)

Bowker, A., Bukowski, W., Zargarpour, S., \& Hoza, B. (1998). A structural and functional analysis of a twodimensional model of social isolation. Merrill Palmer Quarterly, 44, 447-463.

Bryk, A. S., \& Raudenbush, S. W. (1992). Hierarchical linear models: Applications and data analysis methods. Newbury Park, CA: Sage.

Caprara, G. V., Scabini, E., Barbaranelli, C., Pastorelli, C., Regalia, C., \& Bandura, A. (1999). Perceived emotional and interpersonal self-efficacy and good social functioning. Giornale Italiano di Psicologia, 26, $769-789$.

Caspi, A., Elder, G. H., \& Bem, D. J. (1988). Moving away from the world: Life-course patterns of shy children. Developmental Psychology, 24, $824-831$.

Cassidy, J., \& Asher, S. R. (1992). Loneliness and peer relations in young children. Child Development, 63, 350-365.

Cole, D. A., Peeke, L. G., Martin, J. M., Truglio, R., \& Seroczynski, A. D. (1998). A longitudinal look at the relation between depression and anxiety in children and adolescents. Journal of Consulting \& Clinical Psychology, 66, 451-460.

Coplan, R. J. (2000). Assessing nonsocial play in early childhood: Conceptual and methodological approaches. In K. Gitlin-Weiner, A. Sandgrund, \& C. Schafer (Eds.), Play diagnosis and assessment (2nd ed., pp. 563-598). New York: Wiley.

Coplan, R. J., Gavinski-Molina, M. H., Lagace-Seguin, D. G., \& Wichmann, C. (2001). When girls versus boys play alone: Nonsocial play and adjustment in kindergarten. Developmental Psychology, 37, 464-474. 
Curran, P. J., Bauer, D. J., \& Willoughby, M. T. (in press). Testing main effects and interactions in latent curve analysis. Psychological Methods.

Dweck, C. S., \& Leggett, E. L. (1988). A social-cognitive approach to motivation and personality. Psychological Review, 95, 256-273.

Egan, S. K., \& Perry, D. G. (1998). Does low self-regard invite victimization? Developmental Psychology, 34, 299-309.

Eisenberg, N., Fabes, R. A., Karbon, M., Murphy, B. C., Carlo, G., \& Wosinski, M. (1996). Relations of school children's comforting behavior to empathy-related reactions and shyness. Social Development, 5, 330351.

Eisenberg, N., Fabes, R. A., \& Murphy, B. C. (1995). Relations of shyness and low sociability to regulation and emotionality. Journal of Personality \& Social Psychology, 68, 505-517.

Fincham, F. D., Hokoda, A., \& Sanders, R. (1989). Learned helplessness, test anxiety, and academic achievement: A longitudinal analysis. Child Development, 60,138-145.

Gazelle, H., \& Ladd, G. W. (2003). Anxious solitude and peer exclusion: A diathesis-stress model of internalizing trajectories in childhood. Child Development, 74, 257-278.

Hodges, E. V. E., Malone, M. J., \& Perry, D. G. (1997). Individual risk and social risk as interacting determinants of victimization in the peer group. Developmental Psychology, 33, 1032-1039.

Hymel, S., Rubin, K. H., Rowden, L., \& LeMare, L. (1990). Children's peer relationships: Longitudinal prediction of internalizing and externalizing problems from middle to late childhood. Child Development, 61, 2004-2021.

Kerr, M., Lambert, W. W., \& Bem, D. J. (1996). Life course sequelae of childhood shyness in Sweden: Comparison with the United States. Developmental Psychology, 32, 1100-1105.

Kovacs, M. (1980 - 1981). Rating scales to assess depression in school-aged children. Acta Paedopsychiatrica: International Journal of Child \& Adolescent Psychiatry, 46, 305-315.

Ladd, G. W., \& Burgess, K. B. (1999). Charting the relationship trajectories of aggressive, withdrawn, and aggressive/withdrawn children during early grade school. Child Development, 70, 910-929.

Ladd, G. W., \& Profilet, S. M. (1996). The Child Behavior Scale: A teacher-report measure of young children's aggressive, withdrawn, and prosocial behaviors. Developmental Psychology, 32, 1008 - 1024.

Ledingham, J. E., \& Schwartzman, A. E. (1984). A 3-year follow-up of aggressive and withdrawn behavior in childhood: Preliminary findings. Journal of Abnormal Child Psychology, 12, 157 - 168.

Ledingham, J. E., Schwartzman, A. E., \& Serbin, L. A. (1984). Current adjustment and family functioning of children behaviorally at risk for adult schizophrenia. New Directions for Child Development, 24, 99 112.

Maccoby, E. E. (1990). Gender and relationships: A developmental account. American Psychologist, 45, 513 520.

Magnusson, D. (1988). Individual development from an interactional perspective: A longitudinal study. Hillsdale, NJ: Erlbaum.

Metalsky, G. I., Halberstadt, L. J., \& Abramson, L. Y. (1987). Vulnerability to depressive mood reactions: Toward a more powerful test of the diathesis-stress and causal mediation components of the reformulated theory of depression. Journal of Personality \& Social Psychology, 52, 386-393.

Morison, P., \& Masten, A. S. (1991). Peer reputation in middle childhood as a predictor of adaptation in adolescence: A seven-year follow-up. Child Development, 62, 991-1007.

Nolen-Hoeksema, S., Girgus, J. S., \& Seligman, M. E. (1992). Predictors and consequences of childhood depressive symptoms: A 5-year longitudinal study. Journal of Abnormal Psychology, 101, $405-422$.

Paley, V. G. (1992). You can't say you can't play. Cambridge, MA: Harvard University Press.

Raudenbush, S. W., \& Bryk, A. S. (2002). Hierarchical linear models: Applications and data analysis methods (2nd ed. Vol. 1). Thousand Oaks, CA: Sage.

Rodkin, P. C., Farmer, T. W., Pearl, R., \& Van Acker, R. (2000). Heterogeneity of popular boys: Antisocial and prosocial configurations. Developmental Psychology, 36, 14-24.

Rubin, K. H. (1982). Nonsocial play in preschoolers: Necessarily evil? Child Development, 53, 651 - 657. 
Rubin, K. H. (1993). The Waterloo Longitudinal Project: Correlates and consequences of social withdrawal from childhood to adolescence. In K. H. Rubin \& J. B. Asendorpf (Eds.), Social withdrawal, inhibition, and shyness in childhood (pp. 291 - 314). Hillsdale, NJ: Erlbaum.

Rubin, K. H., Chen, X., \& Hymel, S. (1993). Socioemotional characteristics of withdrawn and aggressive children. Merrill-Palmer Quarterly, 39, 518 - 534.

Rubin, K. H., Chen, X., McDougall, P., Bowker, A., \& McKinnon, J. (1995). The Waterloo Longitudinal Project: Predicting internalizing and externalizing problems in adolescence. Development \& Psychopathology, 7, $751-764$.

Rubin, K. H., \& Clark, M. L. (1983). Preschool teachers' ratings of behavioral problems: Observational, sociometric, and social-cognitive correlates. Journal of Abnormal Child Psychology, 11, 273 - 286.

Rubin, K. H., \& Mills, R. S. (1988). The many faces of social isolation in childhood. Journal of Consulting \& Clinical Psychology, 56, 916 - 924.

Rudolph, K. D. (2002). Gender differences in emotional responses to interpersonal stress during adolescence. Journal of Adolescent Health, 30, 3 - 13.

Rudolph, K. D., \& Clark, A. G. (2001). Conceptions of relationships in children with depressive and aggressive symptoms: Social-cognitive distortion or reality? Journal of Abnormal Child Psychology, 29, 41 - 56.

Rudolph, K. D., \& Hammen, C. (1999). Age and gender as determinants of stress exposure, generation, and reactions in youngsters: A transactional perspective. Child Development, 70, 660-677.

Rudolph, K. D., Hammen, C., Burge, D., Lindberg, N., Herzberg, D., \& Daley, S. E. (2000). Toward an interpersonal life-stress model of depression: The developmental context of stress generation. Development \& Psychopathology, 12, 215-234.

Rudolph, K. D., Kurlakowsky, K. D., \& Conley, C. S. (2001). Developmental and social-contextual origins of depressive control-related beliefs and behavior. Cognitive Therapy \& Research, 25, 447-475.

Rudolph, K. D., Lambert, S. F., Clark, A. G., \& Kurlakowsky, K. D. (2001). Negotiating the transition to middle school: The role of self-regulatory processes. Child Development, 72, 929-946.

Scarr, S. (1992). Developmental theories for the 1990s: Development and individual differences. Child Development, 63, 1-19.

Serbin, L. A., Cooperman, J. M., Peters, P. L., Lehoux, P. M., Stack, D. M., \& Schwartzman, A. E. (1998). Intergenerational transfer of psychosocial risk in women with childhood histories of aggression, withdrawal, or aggression and withdrawal. Developmental Psychology, 34,1246-1262.

Skinner, E. A., Zimmer-Gembeck, M. J., \& Connell, J. P. (1998). Individual differences and the development of perceived control. Monographs of the Society for Research in Child Development, 63(2-3, Serial No. 254).

Smucker, M. R., Craighead, W. E., Craighead, L. W., \& Green, B. J. (1986). Normative and reliability data for the Children's Depression Inventory. Journal of Abnormal Child Psychology, 14, 25 - 39.

Stevenson-Hinde, J., \& Glover, A. (1996). Shy girls and boys: A new look. Journal of Child Psychology \& Psychiatry \& Allied Disciplines, 37,181-187.

Stewart, S. L., \& Rubin, K. H. (1995). The social problem-solving skills of anxious-withdrawn children. Development \& Psychopathology, 7, 323-336. 